\section{ANTIBIOTIC PRESCRIBING FOR CHILDREN IN A PEDIATRIC EMERGENCY DEPARTMENT}

D. Konstantelos, S. Psychogiopoulou, T. Syriopoulou, P. Giannakopoulou, A. Koulouri, N. Karli

Pediatrics, General Hospital of Kalamata, Kalamata, Greece

Objectives and aims: The injudicious use of antibiotics is closely related to the development of antibiotic-resistant bacteria. The aim of this study was to evaluate the antibiotic prescribing habits in a pediatric emergency department (PED) .

Methods: We retrospectively examined the records of children up to 14 years old, visiting the pediatric emergency department of a public teaching hospital (Kalamata, Greece) from January to December 2009, which were discharged home with an antibiotic prescription.

Results: During the study period 8732 children visited the PED, while $13,1 \%$ received an antibiotic prescription. 1148 children were identified with a median age of 5 years (0,2 -14 years). $25 \%-75 \%$ of children ranged from 3 to 8 years old. 56,4\% were Greek, $21,6 \%$ were Roma and $22 \%$ of another nationality. A slight prevalence of males $(54,8 \%)$ was noticed. The most common diagnoses leading to an antibiotic prescription were: upper respiratory tract infections $(53,1 \%)$, lower respiratory tract infections $(20,4 \%)$, skin infections and prevention of skin infections $(15,7 \%)$, gastrointestinal infections $(8,4 \%)$ and urinary tract infections $(2,4 \%)$. Fever was present in $63,8 \%$ of cases. Most prescriptions were recorded in March.

Conclusions: Antibiotics are medications frequently prescribed in PED. Upper respiratory tract infections are the most common cause for antibiotic prescription. Physician's continuous therapeutic information and education is necessary in order to prevent inappropriate antibiotic prescribing.

\section{IS HIGH VANCOMYCIN LEVELS IN NEONATES ASSOCIATED WITH HEARING LOSS? A CASE SERIES}

\author{
P. Desai, K. Farrer
}

Neonatology, St Georges Hospital, London, UK

Objectives: To see if there is any evidence of association between high vancomycin levels and hearing loss in neonates.

Methods: This is a case series of 6 neonates who had documented high peak levels of Vancomycin of more than $40 \mathrm{mg} / \mathrm{l}$ with further follow up made regarding hearing loss. A total of 214 neonates received Vancomycin in a tertiary Neonatal unit between Jan 2001 and Dec 2004. Vancomycin was either administered intravenously as daily divided regime or continuous infusion.

Of the 6 Neonates, 3 were born at less than 28 week gestation, 2 were between 32-34 weeks gestation and 1 was a term neonate. Among 6 neonates 1 had high vancomycin levels due to drug error (10 times the prescribed dose) and 2 neonates had preexisting congenital renal problems accounting for the high levels. Vancomycin levels was more than $100 \mathrm{mg} / \mathrm{l}$ in 2 neonates. No intervention apart from reducing or spacing out the doses were made.

Results: There was no demonstrable hearing loss on Auditory Brainstem Response (ABR) for 2 infants done at 1 year of age. Other 4 neonates were followed up and there were no concerns reported by the parents regarding childs hearing.

Conclusion: This small case series suggests that Vancomycin does not appear to be ototoxic even in high levels and adds to the increasing evidence that Vancomycin is not associated with ototoxicity in neonates. Further research needs to be done for association of Vancomycin with hearing loss.

1265

\section{USE OF STEROIDS IN INOTROPE RESISTANT SEPSIS AND AT EXTUBATION IN UK PAEDIATRIC INTENSIVE CARE UNITS - TELEPHONE AUDIT}

\author{
D. Hawcutt, J. Sharpe, K. Parkins \\ Paediatric Intensive Care, Alder Hey Children's \\ Hospital, Liverpool, UK
}

Aims: Steroids are used in the treatment of severe (inotrope resistant) septic shock and for 